\title{
RADIOGRAPHIC ASSESSMENT OF ACCURACY OF FIT FOR DIFFERENT CONICAL CONNECTION ABUTMENTS ON TAPERED IMPLANTS
}

\author{
Shereen M. El Sayed ${ }^{*}$, Alaa Makke** and Khaled Elbanna***
}

\begin{abstract}
Statement of the problem: Custom-made cast gold abutment has proven its superiority for decades, however the incurring high price has led to the introduction of cast base-metal abutments which has to be tested to justify its use as a valid alternative.
\end{abstract}

Purpose: The aim of this study was to evaluate the accuracy of fit between implant and abutment using different types of abutments.

Methods: A total of 32 titanium implants (NobleReplace conical connection, Noble Biocare, Sweden) with $3.5 \mathrm{~mm}$ diameter, $12 \mathrm{~mm}$ length and internal conical connection were used in this study. All implants were randomly divided into four equal groups $(n=8)$ according to the type of the abutment used as follows: Group I (Control Group): Ready-made Titanium abutment (Snappy abutment, Noble Biocare, AB, Sweden). Group II: Custom-made Gold abutment (Gold Adapt cast abutment, Noble Biocare, AB, Sweden). Group III: Custom-made Co-Cr abutment with prefabricated machined Co-Cr base (Co-Cr base, Dess, Spain). Group IV: Custom-made Fully Casted Co-Cr abutment (Dess, Spain). Abutments for groups II, III, IV were fabricated using the conventional casting technique to obtain custom-made gold abutments for group II and custommade Co-Cr abutments for groups III, IV. All the abutments were screwed to their respective implants and tightened at $35 \mathrm{~N} / \mathrm{cm}$ using manual Torque Wrench. The $\mathrm{x}$-ray sensor was placed parallel to the implant and a radiograph was taken for each sample. The distance from the end of the base of the abutment till the beginning of the screw holes of the implant was measured in $\mathrm{mm}$ for all samples by the same operator. Data were gathered, organized in tables and statistically studied.

Results: Results showed that Group IV (Fully casted Co-Cr abutment) had the statistically significantly highest mean value. Group III (Custom-made with Co-Cr Base abutment) showed statistically significantly lower mean value. There was no statistically significant difference between

* Associate Professor, Fixed Prosthodontics Department, Faculty of Dentistry, Cairo University, Egypt. Associate Professor, Fixed Prosthodontics Division, Oral and Maxillofacial Surgery Department, Faculty of Dentistry, Umm Al-Qura University, Makkah, KSA.

** Assistant Professor, Implantology Division, Oral and Maxillofacial Surgery Department, Faculty of Dentistry, Umm Al-Qura University, Makkah, KSA.

*** Assistant Professor, Fixed Prosthodontics Division, Oral and Maxillofacial Surgery Department, Faculty of Dentistry, Umm Al-Qura University, Makkah, KSA. 
Group I (Ready-made Ti abutment) and Group II (Custom-made Au abutment); both showed the statistically significantly lowest mean values.

Conclusions: Within the limitations of this study, it was concluded that: Low-priced Custommade $\mathrm{Co}-\mathrm{Cr}$ abutments with prefabricated $\mathrm{Co}-\mathrm{Cr}$ base revealed promising results. Casted connections don't seem to be a good alternative to machined connections unless a strict standardizations of the technique sensitive casting process takes place. Due to the tapered connection, it is hard to detect any seating discrepancy. While Conical connections rely mainly on the accuracy of the machined surfaces, casting variables may affect the quality of the connection. The use of dental radiography seems to be an acceptable clinical reliable method for precise detection of the fit of conical connections

KEYWORDS: Ready-made titanium abutment, custom-made gold abutment, Custom-made $\mathrm{Co}-\mathrm{Cr}$ abutment with prefabricated machined $\mathrm{Co}-\mathrm{Cr}$ base, custom-made fully casted $\mathrm{Co}-\mathrm{Cr}$ abutment, conical connection, tapered implant, abutment fit, radiographic technique.

\section{INTRODUCTION}

Nowadays, Dental two-piece implant-supported prostheses are commonly used for replacement of missing teeth with the advantage of keeping neighboring teeth intact without preparation. ${ }^{(1)}$

Two-piece implant system involves an implant placed in the bone with an abutment connected to it by a screw and the final prosthesis will be constructed over the abutment. ${ }^{(2,3)}$ Accordingly, these units end up with a lot of interfaces between implant system parts. ${ }^{(3)}$ A great attention must be paid to the connection between the implant and the abutment as it is considered a critical interface that will affect the long-term survival rate of the implantsupported prosthesis. ${ }^{(4,5)}$

Currently, there are several implant-abutment connection options so that the prosthodontist will be able to pick the most reliable choice according to the clinical indications. ${ }^{(3)}$ The most common problem occurring at the implant-abutment interface is the micro-gaps that could result after tight closure of the abutment screws. ${ }^{(6,7)}$ These gaps could give rise to bacterial accumulation and difficulty in excess cement removal leading to a greater risk of peri-implantitis that will be followed by bone resorption and implant loss ${ }^{(8,9)}$ which is considered as a biological failure. ${ }^{(10-14)}$ Additionally, these micro-gaps are correlated to the screw loosening drawback with accompanied stresses at the implant cervical area ${ }^{(14,15)}$ The micro-gap can be enlarged by the screw loosening resulting in screw fractures or breakage of the overlying abutments and prosthetic frameworks. ${ }^{(16,17)}$ Besides, these micro-gaps will cause uneven occlusal forces distribution producing non-axial loading over the entire implant surface..$^{(18)}$ All these complications are considered mechanical failure. (2)

In attempt to prevent all the aforementioned failures that are related to micro-gaps between abutment and implant, the ongoing development of more dependable implant-abutment connections with several evolution in materials and precision manufacturing of implant parts has gained popularity at the present time. ${ }^{(19-22)}$ Precise and passive fit between different implant parts in conjunction with biocompatibility and sufficient mechanical properties are listed among the most important properties that must be present in implant abutments to fulfill biological, mechanical and esthetic requirements and avoid further complications within the implant system. ${ }^{(1,23,24)}$

Different prosthetic systems offer either readymade or cast custom-made abutments to fit different clinical situations. The pre-machined ready-made abutments are introduced with the benefit of reduction of the mechanical failure risk in addition to their low original price. ${ }^{(1,25)}$ Conversely, the 
custom-made gold cast abutments were presented in the market to fit for every patient individual tooth in different clinical situations with the advantage of tailoring the emergence profile precisely from the implant to the abutment and then finally to the superstructure, reaching the best esthetic results. ${ }^{(1)}$ The drawbacks of the gold custom-made abutments are their high cost and the normal casting failures that could result during the casting procedures. ${ }^{(1)}$

Base-metal alloys have been always used as an alternative to noble-metal alloys in prosthodontics as they propose lower price than gold alloys in addition to reasonable biocompatibility and clinical performance. ${ }^{(26)}$ However, base-metal alloys are considered more sensitive to casting fabrication process leading to compromised precise restoration. (27) Accordingly, a prefabricated $\mathrm{Co}-\mathrm{Cr}$ base with plastic burnout sleeve was introduced in the market to obtain a cheap substitute for precious alloys. ${ }^{(28)}$ By introduction of this new option, we can achieve low-priced Co-Cr custom-made abutment with or without pre-machined Co-Cr base to expand the use of custom-made abutments in different situations.

Hence, the aim of this study was to evaluate the accuracy of fit between implant and abutment using different abutment types. The null hypothesis was that different abutment types would not affect the fit at implant-abutment interface.

\section{MATERIALS AND METHODS}

A total of 32 titanium implants (NobleReplace conical connection, NobleBiocare AB, Sweden) with $3.5 \mathrm{~mm}$ diameter, $12 \mathrm{~mm}$ length and internal conical connection were used in this study.
All implants were randomly divided into four equal groups $(n=8)$ according to the type of the abutment used as follows:

Group I (Control Group): Ready-made Titanium abutment (Snappy abutment, NobleBiocare, AB, Sweden).

Group II: Custom-made Gold abutment (Gold Adapt cast abutment, NobleBiocare AB, Sweden).

Group III: Custom-made Co-Cr abutment with prefabricated machined $\mathrm{Co}-\mathrm{Cr}$ base (Co-Cr base, Dess, Spain).

Group IV: Custom-made Fully Casted Co-Cr abutment (Dess, Spain).

Sample grouping was presented in Table (1).

Acrylic resin powder and liquid (Major Ortho, Italy) were mixed and poured in a silicone ice cube tray with 30x30x30mm dimensions. An implant was submerged vertically in the middle of each cube till $1 \mathrm{~mm}$ below the crest of the implant and stabilized in place using bobby pins and left overnight to allow complete setting of the acrylic resin.

A cylindrical temporary abutment (Noble Biocare AB, Sweden) was screwed to each implant and the whole assembly was put on the table of a milling machine (Bego Paraskope, Germany). A long cylindrical acrylic bur was attached to the milling machine and was rested on the side of the temporary abutment and the milling machine table was moved until the bur rested completely parallel on the temporary abutment at which the table was fixed. The side wall of the acrylic cube was milled parallel to the temporary abutment. This was made to ensure that the side wall of the cube was parallel to the implant inside the acrylic resin.

TABLE (1): Sample Grouping.

\begin{tabular}{|c|c|c|c|c|}
\hline \multirow{4}{*}{ Groups } & I & II & III & IV \\
\cline { 2 - 5 } & $\begin{array}{c}\text { Ready-made } \\
\text { Titanium abutment } \\
(\text { Control })\end{array}$ & $\begin{array}{c}\text { Custom-made Gold } \\
(\mathrm{Au}) \text { abutment }\end{array}$ & $\begin{array}{c}\text { Custom-made Co-Cr abutment } \\
\text { with prefabricated machined } \\
\text { Co-Cr base }\end{array}$ & $\begin{array}{c}\text { Custom-made } \\
\text { Fully Casted Co-Cr } \\
\text { abutment }\end{array}$ \\
\hline
\end{tabular}


Group I samples did not need any procedures as they were ready-made, whereas for groups II, III, IV implant analogues were stabilized in improved stone. Twenty-four castable abutments were connected to the lab analogues of the predetermined implants assigned for these groups. Wax patterns were fabricated over the burn-out sleeves with $4.5 \mathrm{~mm}$ diameter and $7 \mathrm{~mm}$ length. Standardization of wax patterns was done using prefabricated twopiece addition silicon matrix (3M Express STD, USA) constructed on the first wax pattern for the first sample in group II. Dimensions were rechecked after finalizing wax patterns for all castable groups using digital caliper (Mituotoyo, Japan). Spruing, investing and casting were performed conventionally according to manufacturers' instructions using high noble ceramo-metal alloy (Eclipse, Dentsply Sirona, USA) to produce custom-made gold abutments for samples of group II and ceramo-metal cobalt chromium alloy (Wirobond, Bego, Germany) to produce custom-made Co-Cr abutments for samples of groups III and IV.

All the castable abutments were finished and polished according to manufacturers' instructions. All the dental laboratory work was performed in the same dental laboratory by the same dental technician.

The temporary abutments were removed and all the abutments of Groups I, II, III and IV were connected to their respective implants and tightened with titanium screws at $35 \mathrm{~N} / \mathrm{cm}$ using manual Torque Wrench Prosthetic and Screwdriver Machine Unigrip (Noble Biocare AB, Sweden) and left for 10 minutes then they were tightened again to the same torque of $35 \mathrm{~N} / \mathrm{cm}$

The locator ring and the metallic arm of an x-ray holder device (RINN XCP, Dentsply Sirona, USA) were secured to the cone of an $\mathrm{X}$-ray machine (Expert DC, Gendex Dental Systems, USA) using duct tape making sure that the metallic arm was parallel to the cone $\left(0^{\circ}\right)$. The acrylic cube was attached by duct tape to an anterior digital film holder and bite block from the milled side to ensure that the implant was parallel to size 2 x-ray sensor (Gendex GXS 700, Gendex Dental Systems, USA) then attached to the metallic arm of the x-ray film holder. Fig. (1)

$\mathrm{X}$-ray exposure was done at $70 \mathrm{KV}$ and $0.7 \mathrm{~mA}$ for 0.2 seconds. The images were imported to an image measuring software (KLONK Image Measurement, Image Measurement Corporation, USA). The ruler was calibrated by the fixed dimension of the implant platform $(3.5 \mathrm{~mm})$ and the distance from the end of the base of the abutments till the beginning of the screw holes of the implants (Distance $\mathrm{X}$ ) was measured in millimeters for all the samples by the same operator. Fig. (2). Images for representative samples of each group were shown in Figs (3-6).

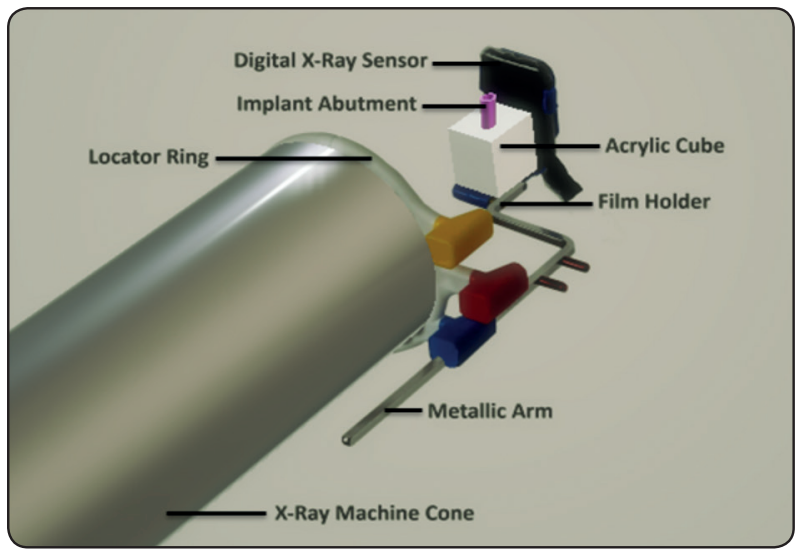

Fig. (1): Diagram showing radiographic imaging set-up.

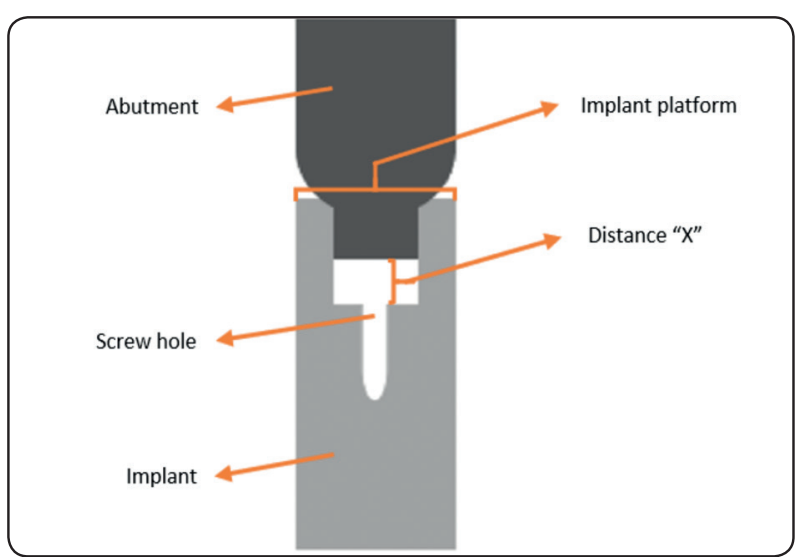

Fig. (2): Schematic diagram showing measurement method. Distance " $X$ " represents the distance from the end of the base of the abutment till the beginning of the screw hole of the implant. 


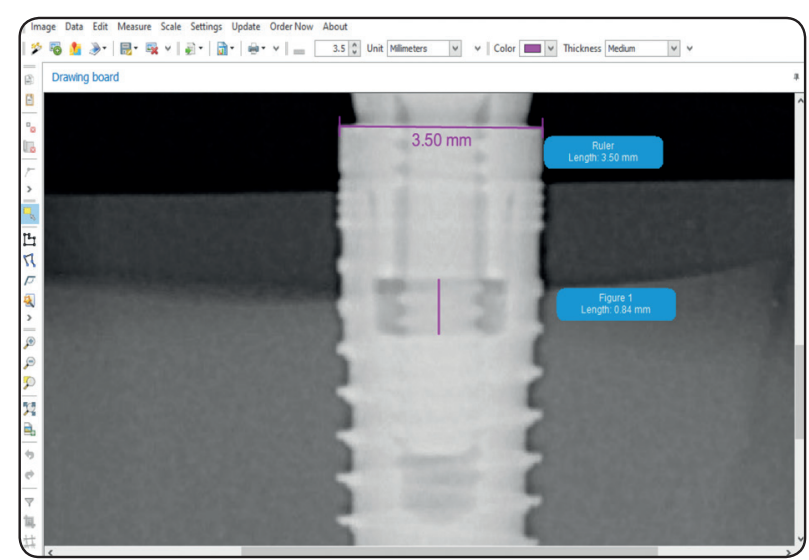

Fig. (3): Radiograph showing representative sample for Group I: Ready-made Titanium abutment (Control).

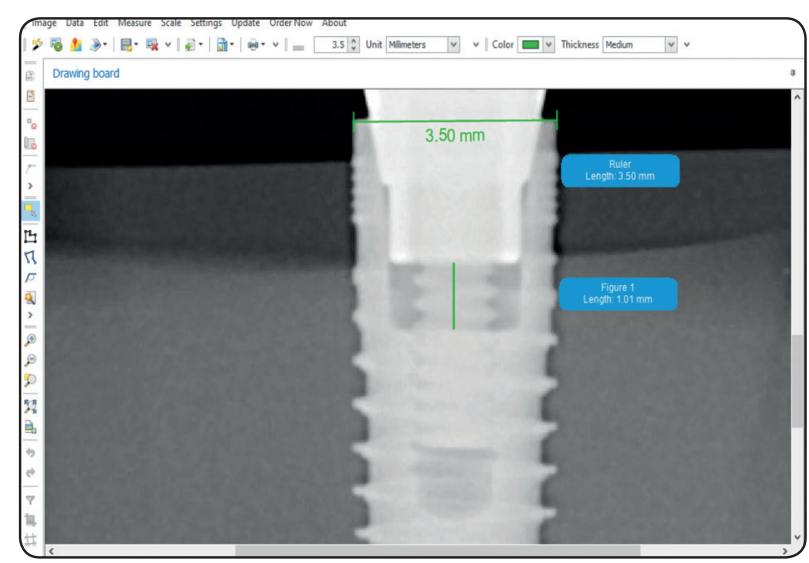

Fig. (5): Radiograph showing representative sample for Group III: Custom-made abutment with $\mathrm{Co}-\mathrm{Cr}$ base.

Data were gathered, organized in tables and statistically studied.

\section{RESULTS}

Numerical data were studied for normality by examining the distribution of data and using tests of normality (Kolmogorov-Smirnov and ShapiroWilk tests). Data revealed normal (parametric) distribution. Data were represented as mean, standard deviation (SD) and 95\% Confidence Interval (95\% CI) for the mean values. One-way Analysis of Variance (ANOVA) test was performed to compare between the four groups. Bonferroni's post-hoc test was utilized for pair-wise comparisons when ANOVA test is significant. The significance

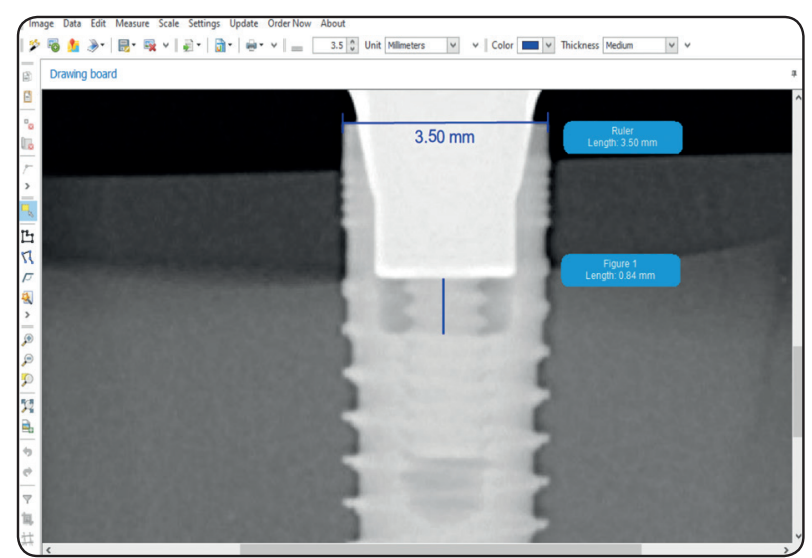

Fig. (4): Radiograph showing representative sample for Group II: Custom-made Gold Abutment.

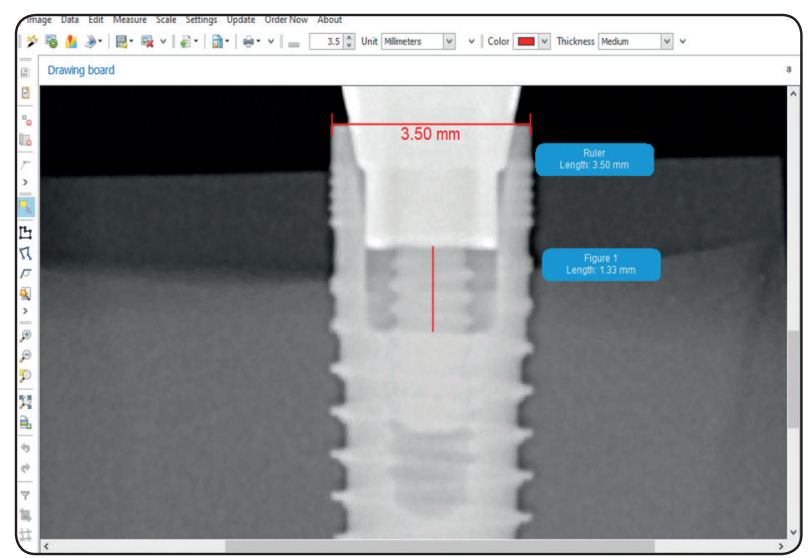

Fig. (6): Radiograph showing representative sample for Group IV: Co-Cr Fully casted Co-Cr abutment.

level was set at $\mathrm{P} \leq 0.05$. Statistical analysis was performed with IBM SPSS Statistics for Windows, Version 23.0. Armonk, NY: IBM Corp.

There was a statistically significant difference between the groups $(P$-value $<0.001$, Effect size $=0.962)$. Pair-wise comparisons between the groups revealed that Group IV (Fully casted Co$\mathrm{Cr}$ abutment) showed the statistically significantly highest mean value. Group III (Custom-made with Co-Cr Base abutment) showed statistically significantly lower mean value. There was no statistically significant difference between Group I (Ready-made Ti abutment) and Group II (Custommade Au abutment); both showed the statistically significantly lowest mean values. Table (2), Fig. (7). 
TABLE (2). Mean, standard deviation (SD), 95\% Confidence Interval (95\% CI) values, results of one-way ANOVA test and Bonferroni's post-hoc test for comparison between the four groups.

\begin{tabular}{|c|c|c|c|c|c|}
\hline Group & $\begin{array}{l}\text { Mean } \\
(\mathrm{mm})\end{array}$ & SD & $95 \% \mathrm{CI}$ & $P$-value & $\begin{array}{c}\text { Effect size } \\
\text { (Eta squared) }\end{array}$ \\
\hline Ready-made Ti abutment (control) & $0.856^{\mathrm{C}}$ & 0.015 & $0.837-0.875$ & \multirow{4}{*}{$<0.001 *$} & \multirow{4}{*}{0.962} \\
\hline Custom-made Au abutment & $0.844^{\mathrm{C}}$ & 0.017 & $0.823-0.865$ & & \\
\hline Custom-made with $\mathrm{Co}-\mathrm{Cr}$ base abutment & $1.018^{\text {в }}$ & 0.034 & $0.976-1.061$ & & \\
\hline Fully casted Co-Cr abutment & $1.296^{\mathrm{A}}$ & 0.07 & $1.209-1.383$ & & \\
\hline
\end{tabular}

*: Significant at $P \leq 0.05$, Different superscripts are statistically significantly different according to Bonferroni's post-hoc test

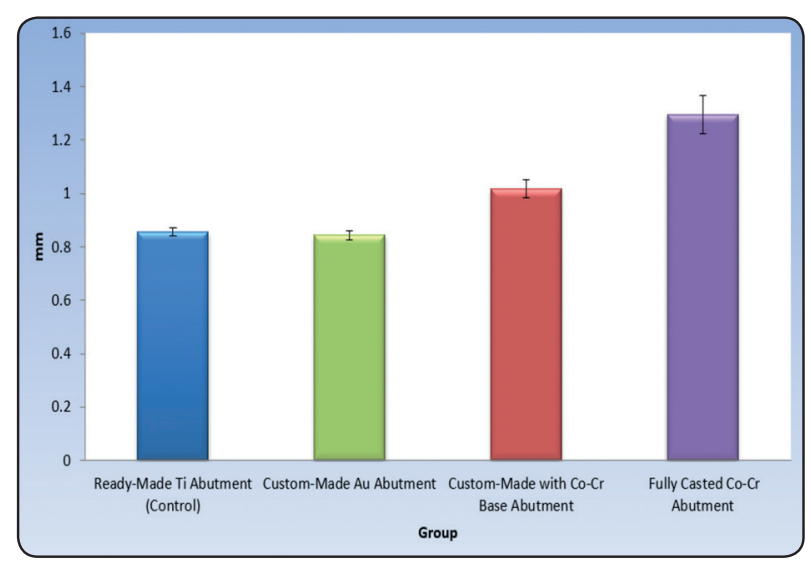

Fig. (7). Bar chart representing mean and standard deviation values for measurements in the four groups

\section{DISCUSSION}

Long-term success rate of implant-supported prostheses has gained wide popularity in dental research owing to the widespread applications of implants in rehabilitation of missing teeth. The reliability of the implant abutment interface is considered one of the critical factors that must be precisely studied to reduce implant failures. Factors affecting the integrity and accuracy of implant-abutment connections include design and precision of fit of the attached parts as well as the materials used. Misfit at this critical link; implant and abutment will cause screw loosening with subsequent microleakage leading to failure of the whole system.
Many implant-abutment connection designs have been developed to strengthen this weak link. The early invented external hexagon connection resulted in great possibility of screw loosening problems due to high incidence of rotational misfit giving rise to improper microbial seal. ${ }^{(26,29,30)}$ The shift towards the commonly used nowadays internal connection designs with alteration of the connection part inside the implant body and at a lower level to the implant coronal portion has given this design its unique advantage. ${ }^{(31,32)}$ The internal implantabutment design resulted in better occlusal forces distribution and improved abutment stability in consequence of lowering of the rotational centre and protection of the retention screws, thus, resisting excessive lateral forces. ${ }^{(2,33)}$ Moreover, this internal connection confirms appropriate abutment seating that ensures better microbial seal as well as better aesthetic outcomes. ${ }^{(32)}$

On the top of that and in an attempt to decrease the micro-gaps between implants and abutments as much as possible, a superior type of internal connection was introduced depending on a premachined base with significant friction offered at the abutment-implant interface. ${ }^{(34)}$ This type is called the conical connection which resulted in decreased incidence of microleakage and screw loosening. ${ }^{(35)}$ All the implant-abutment connections used in this 
study belonged to the internal conical connection group as it is proven to have best marginal fit along all types. ${ }^{(36-41)}$

Different techniques for detection of the microgaps at the implant-abutment connections were used previously in the literature. These techniques include stereomicroscopes, micro-tomography ${ }^{(26,42)}$, scanning electron microscope ${ }^{(43,44,45)}$, scanning laser microscopy ${ }^{(46)}$, optical microscopy ${ }^{(43,47)}$, optical coherence tomography ${ }^{(3)}$ and the most popular commonly used simple intraoral radiography. ${ }^{(16,18,48,49)}$

The dental radiography assessment method was used in this study owing to its simplicity and clinical availability thus simulating a real situation that could be used clinically. This method was assessed previously by several authors ${ }^{(18,48,49)}$ who proved its clinical reliability. This approach was in accordance with Ormaechea et al ${ }^{(49)}$ who stated that radiographic technique can be used to ensure the fit at implant-abutment connection and can measure gaps of at least $21 \mu \mathrm{m}$. However, radiographic technique may show some limitations leading to misleading results. Therefore, the implant-abutment assemblies were placed in a special setup in the film holder to guarantee that the $\mathrm{x}$-ray sensor is parallel to the implant long axis and the $\mathrm{x}$-ray beam hit both the sensor and the implant perpendicularly. This was consistent with Alikhasi et al ${ }^{(48)}$ who highlighted the importance of the parallel positioning of the $\mathrm{x}$-ray film to the long axis of the implant and perpendicular projection of the $\mathrm{x}$-ray beam to ensure the precision of the radiograph in measurements of gaps.

The $\mathrm{x}$-ray tube angulation was adjusted to be zero degrees in all samples as it was previously proven that the best angulation of the $\mathrm{x}$-ray tube to detect gaps is $0^{\circ}$. Cameron et al ${ }^{(50)}$ and Liedke et al ${ }^{(51)}$ concluded that implant-abutment micro-gaps can be identified accurately if the x-ray tube was adjusted up to $15^{\circ}$ to $20^{\circ}$.

It is of great significance to mention that all the measurements performed in this study for all samples are in points along the inner circumference of the implant-abutment interface owing to the shape of the chosen type of internal conical connections which reveals almost no gaps and no precise measuring points due to the lack of contact between the implant and the abutment at the outer circumference. On the contrary, most previous studies examining the implant-abutment gaps concentrated on measuring the gap at the outer circumference of the implant-abutment interface ${ }^{(44,46,52-55)}$ which obscures the comparison of the results of this study to the previous studies.

The measurement obtained from this study were the measurements of the distance between the lower circumference of the base of the abutments and the screw hole as these points are fixed, standardized in all the implants and abutments, easily identified in the radiograph and can reveal the level of seating of the abutments. Measurement of gap distance at the implant-abutment interface is not viable as the abutment would always contact the implant at the smallest fitting diameter of the conical base. Several authors have reported this finding and agreed that there was always a few-millimeter contact between the conical connection with the internal surface of the implant and as the two surfaces appeared to be thoroughly in contact, it was difficult to distinguish the micro-gap at the interface. ${ }^{(15,56,57)}$

Titanium screws were used to tighten the abutments of all the groups in this study to standardize the elongation of the threads and cervical part of the screws during tightening as described by Kim and Shin. ${ }^{(1)}$ The tightening torque was applied twice in 10-minute interval to compensate for the decrease in preload due to settling of the screw surfaces ${ }^{(1)}$.

The results of this study revealed that there was a statistically significant difference between the groups, thus, the null hypothesis was rejected. Ready-made titanium abutments (group I) and custom-made gold abutments (group II) showed the least mean values with no statistical significance 
difference between them. This may be due to the precise and accurate intimate fit between the premachined parts in group I which may have led to proper stability along the implant-abutment interface. Remarkably, custom-made gold abutment exhibited comparable results to the ready-made titanium abutments. This may be due to the wellknown accuracy of the casting process of gold alloys in addition to the presence of the metallic premachined base which may have resulted in better fit at the implant-abutment interface.

This finding is in accordance with the results of Lalithamma et al ${ }^{(58)}$ who found comparable results between ready-made titanium abutments and premachined cast gold with plastic sleeve abutments with no statistically significant difference between them.

Regarding groups III and IV, the results showed that Co-Cr fully casted abutments (Group IV) have the highest mean values. This may be attributable to the technique sensitivity of the casting process of the Co-Cr alloys due to high melting point and oxidation which decreases the restoration accuracy. This was assured previously in the literature. ${ }^{(27,58)}$

By analysing the results of group III which represented castable $\mathrm{Co}-\mathrm{Cr}$ also but with prefabricated machined $\mathrm{Co}-\mathrm{Cr}$ base, a great improvement in the mean values can be emphasized. The metal part in the pre-machined $\mathrm{Co}-\mathrm{Cr}$ base did not deform during the casting process because its melting point is higher than the investment heating temperature and thus keeping the dimensions constant at this critical interface.

On the other hand, the fully casted $\mathrm{Co}-\mathrm{Cr}$ abutments casting resulted in a dimensional change at the interface which might have led to the increased mean values of this group. This was in agreement with Moris et al ${ }^{(26)}$ who studied the effect of different casting techniques on vertical marginal fit to the implant using Co-Cr alloys and reached the same conclusion. A further possible reason for the incomplete seating of the fully casted $\mathrm{Co}-\mathrm{Cr}$ abutment is the lack of opposing platforms to be seated on each other on the outer circumference of the implant-abutment interface. That makes it difficult for the dental technician to assess the fit and seating of the abutment after casting and during the finishing and polishing procedures as it involves not only the coronal part of the abutment but also the critical connection area itself unlike the other three groups where the connection is always machined. The incomplete seating of these abutments was demonstrated by the highest mean values and the obvious incomplete screw engagement in comparison to the other groups. This problem might not show as gap due to the tapered nature of the connection, nevertheless, it is more likely for such abutments to exhibit more screw loosening after functioning which may lead to biological and mechanical failures.

This study has some limitations. Cyclic loading and moist oral environment simulation might have affected the results differently. Thus, further investigations must be done to detect the effect of these factors on the fit between the implant and the abutment. Moreover, the use of a digital torque controller may have provided a more standardized torqueing of the abutments. Finally, biological compatibility of Co-Cr abutments inside the sulcus area should be investigated to complement the results of this study.

\section{CONCLUSIONS}

Within the limitations of this study, we can conclude that:

1. Low-priced Custom-made Co-Cr abutments with prefabricated $\mathrm{Co}-\mathrm{Cr}$ base revealed promising results.

2. Casted connections do not seem to be a good alternative to machined connections unless a 
strict standardizations of the technique sensitive casting process takes place.

3. Due to the tapered connection, it is hard to detect any seating discrepancy. While conical connections rely mainly on the accuracy of the machined surfaces, casting variables may affect the quality of the connection.

4. The use of dental radiography seems to be an acceptable clinical reliable method for precise detection of the micro-gaps at the implantabutment interface.

\section{Conflict of interest}

The authors of this study declare that they have not received any financial funding from any of the companies mentioned in this study.

\section{REFERENCES}

1. Kim E and Shin S. Influence of the implant abutment types and the dynamic loading on initial screw loosening. J Adv Prosthodont 2013;5:21-8.

2. Kofron M, Carstens M, Fu C, Wen H. In vitro assessment of connection strength and stability of internal implant-abutment connections. Clinical Biomechanics 2019;65:92-9.

3. Kikuchi K, Akiba N, Sadr A, Sumi Y, Tagami J, Minakushi S. Evaluation of the marginal fit at implant -abutment interface by optical coherence tomography. J Biomedical Optics 2014;19(5):055002.

4. Gigandet M, Bigolin G, Faoro F, Burgin W, Bragger U. Implants with original and non-original abutment connections. Clin Implant Dent Relat Res 2014;16:303-311.

5. Lang LA, Sierraalta M, Hoffensperger M, Wang RF. Evaluation of the precision of fit between the Procera custom abutment and various implant systems. Int J Oral Maxillofac Implants 2003;18:652-8

6. Kano SC, Binon PP, Curtis DA. A classification system to measure the implant-abutment microgap. Int J Oral Maxillofac Implants 2007;22(6):879-885.

7. Yao KT, Kao HC, Cheng CK, Fang HW, Huang CH, Hsu ML. Mechanical performance of conical implant-abutment connections under different cycle loading conditions. J Mech Behav Biomed Mater 2019;90:426-432.
8. Piatelli A, Scarano A, Paolantonio M, Assenza B, Leghissa GC, Di Bonaventura B, Catamo G, Piccolimini R. Fluids and microbial penetration in the internal part of cementretained versus screw-retained implant-abutment connections. J Periodontol 2001;72(9):1146-1150.

9. Broggini N, McManus LM, Hermann JS, Medina Ru. Persistent acute inflammation at the implant-abutment interface. J Dent Res 2003;82(3):232-7.

10. Carinci F, Lauritano D, Cura F, Lopez MA, Bassi MA, Confalone L, Pezzeti F. Prevention of bacterial leakage at implant-abutment connection level: An in vitro study of the efficacy of three different implant systems. J Biol Regul Homeost Agents 2016;30(1)69-73.

11. Lopez MA, Bassi MA, Confalone L, Gaudio RM, Lombardo L, Lauritano D. The influence of "conical plus octagonal" internal connection on implant survival and success rate. A retrospective study of 66 fixtures. J Biol Regul Homeost Agents 2016;30(1):49-54.

12. Coelho PG, Sudack P, Suzuki M, Kurtz KS, Romanos GE, Silva NR. In vitro evaluation of the implant abutment connection sealing capability of different implant systems. J Oral Rehabil 2008;35(12):917-924.

13. Harder S, Dimaczek B, Acil Y, Terheyden H, Freitag-Wolf, Kern M. Molecular leakage at implant-abutment connection: in vitro investigation of tightness of internal conical implant-abutment connections against endotoxin penetration. Clin Oral Investig 2010;14(4):427-432.

14. Jemt T. Failures and complications in 391 consecutively inserted fixed prostheses supported by Brånemark implants in edentulous jaws: a study of treatment from the time of prosthesis placement to the first annual checkup. Int J Maxillofac Implants 1991;6(3):270-6

15. Scarano A, Valbonetti L, Degidi M, Pecci R, Piatteli A, de Oliviera PS, Perotti V. Implant-abutment contact surfaces and microgap measurements of different implant connections under 3-dimensional x-ray microtomography. Implant Dentistry 2016;25(5):656-662.

16. Shahin C, Ayildiz S. Correlation between microleakage and screw loosening at implant-abutment connection. J Adv Prosthodont 2014;6:35-8.

17. Smedberg JL, Nilner K, Frikholm A. A six-year follow-up study of maxillary overdentures on osseointegrated implants. Eur J Prosthodont Rest Dent 1999;7:51-6.

18. Papavassiliou H, Kourtis S, Katerelou J, Chronopoulos V. Radiographical evaluation of the gap at the implant-abutment interface. J Esthet Restor Dent 2010;22:235-251. 
19. Asvanund P, Morgano SM. Photoelastic stress analysis of external versus internal implant-abutment connections. J Prosthet Dent 2011;106:266-71.

20. Freitas AC Jr, Bonfante EA, Rocha AP, Silva NR. Effect of implant connection and restoration design (screwed vs. cemented) in reliability and failure modes of anterior crowns. Eur J Oral Sci 2011;119:323-30.

21. Gracis S, Michalakis K, Vigolo P, Vult von Steyen P, Zwahlen M, Sailer I. Internal vs. external connections for abutments/reconstructions: a systematic review. Clin Oral Implants Res 2012;23:202-16.

22. Coppede AR, Faria AC, de Mattos Mda G, Rodrigues RC, Shibli JA, Ribiero RF. Mechanical comparison of experimental conical-head abutment screws with conventional flat-head abutment screws for external-hex and internal tri-channel implant connections: an in vitro evaluation of loosening torque. Int J Oral Maxillofac Implants 2013;28:321-9.

23. Sawase T, Wennerberg A, Hallgren C, Albrekrsson T, Baba K. Chemical and topographical surface analysis of five different implant abutments. Clin Oral Implants Res 2000;11:44-50.

24. Heydecke G, Sierraalta M, Razoog ME. Evolution and use of aluminum oxide single tooth implant abutments: a short review and presentation of two cases. Int J Prosthodont 2002;15:488-93.

25. Tavarez RRJ, Bonachela WC, Xible AA. Effect of cyclic load on vertical misfit of prefabricated and cast implant single abutment. J App Oral Sci 2011;19:16-21 .

26. Moris ICM, Monteiro SB, Martins R, Ribeiro RF, Gomes EA. Influence of manufacturing methods of implantsupported crowns on external and internal marginal fit: A micro-CT analysis. Biomed Research Int 2018;5049605

27. Gómez-Cogolludo P, Castillo-Oyague C, Lynch D, Saurez-Garcia MJ. Effect of electric arc, gas oxygen torch and induction melting techniques on the marginal accuracy of cast base-metal and noble metal-ceramic crowns. J Dentistry 2013;41(9):826-831.

28. Dess Dental Smart Solution. CoCr Base: Extened instuctions of use (English Version). INS-02-MUL-02.

29. Pardel-Peláez B, and Montero J. Preload loss of abutment screws after dynamic fatigue in single implant-supported restorations. A systemic review. J Clin Exp Dent 2017; 9(11):e1355-e1361 .

30. Shetty M, Parasad K, Shetty N, Jaiman R. Implant abutment connection: biomechanical perspectives. Netteuni J Health Sci 2014;4:47-53.
31. Sarafraz H, Paulose A, Shenoy KK, Hussain A. A threedimensional finite element analysis of a passive and friction fit implant abutment interface and the influence of occlusal table dimension on the stress distribution pattern on the implant an surrounding bone. J Indian Prosthodont Soc 2015;15(3):229-236.

32. Lauritano D, Moreo G, Lucchese A, Viganoni C, Limongelli L, Carinci F. The impact of implant-abutment connection on clinical outcomes and microbial colonization: a narrative review. Materials 2020;13:1131.

33. Duraisami R, Krishnan CS, Ramasubramanian H, Sampathkumar J, Mariappan S, Sivaprakasam AN. Compatibility of non-original abutments with implants: evaluation of microgap at the implant-abutment interface, with original and non-original abutments. Implant Dent 2019;28:289295.

34. Mencio F, Papi P, DiCarlo S, Pompa G. Salivary bacterial leakage into implant-abutment connections: preliminary results of an in vitro study. Eur Rev Med Pharmacol Sci 2016;20:2476-2483

35. Tsuruta K, Ayukawa Y, Matsuzaki T, Kihara M, Koyano $\mathrm{K}$. The influence of implant-abutment connection on the screw loosening and microleakage. Int J Implant Dent 2018;4(1):11-6.

36. Assenza B, Tripodi A, Scarano A, Perrotti V, Piattelli A, Iezzi G, D'Ercole S. Bacterial leakage in implants with different implant-abutment connections: an in vitro study. J periodontal 2012;83:491-497.

37. D'Ercole S, Scarano A, Perrotti V, Mulatinho J, Piattelli A, Iezzi G, Tripodi D. Implants with external hexagon and conical implant-abutment connections: an in vitro study of the bacterial contamination. J Oral Implantol 2014;40:30-36.

38. Tripodi D, Vantaggiato G, Scarano A, Perrotti V, Piattelli A, Iezzi G, D'Ercole S. An in vitro investigation about the bacterial leakage in implants with internal hexagon and morse taper implant-abutment connections. Implant Dent 2012;21:335-339.

39. Faroux MA, Lavallois B, Yachou J, Torres JH . Assessment of leakage at the implant abutment connection using a new gas flow method. Int J Oral Maxillofac Implants 2012;27:1409-1412.

40. Do Nascimento C, Kirsten Miani P, Pedrazzi V, Gonçalves RB, Ribeiro RF, Faria AC, Macedo AP, Ferreira de Albuquerque Jr R . Leakage of saliva through the implant-abutment interface: in vitro evaluation of three different im- 
plant connections under unloaded and loaded conditions. Int J Oral Maxillofac Implants 2102;27:551-560.

41. Jaworski ME, Melo AC, Piche CM, Sartori IA. Analysis of bacterial seal at the implant-abutment interface in external hexagon and morse taper connection implants. An in vitro study using new methodology. Int J Oral Maxillofac Implants 2012;27:1091-1095.

42. Krasanaki ME, Pellekanos S, Andreiotelli S, Koutayas O, Eliades G. X-ray microtomographic evaluation of the influence of two preparation types on marginal fit of CAD/ CAM alumina copings: a pilot study. Int J Prosthodont 2012;25(2):170-2.

43. Fokas G, Ma L, Chronopoulos V, Janda M, Mattheos N. Differences in micromorphology of the implant-abutment junction for original and third party abutments on a representative dental implant. J Prosthet Dent 2019;121:143-50.

44. Sola-Ruiz MF, Selva-Otaolaurruchi E, Senent-Vicente G, González-de-Cossio I, Amigó-Borrás V . Accuracy combining different brands of implants and abutments. Med Oral Patol Oral Cir Bucal 2013;18:332-6.

45. Hamiliton A, Judge RB, Palamara J, Evans C . Evaluation of the fit of CAD/CAM abutments. Int J Prosthodont 2013;26:370.

46. Tsuge T, Hagiwara Y, Matsumura H. Marginal fit and microgaps of implant-abutment interface with internal antirotation configuration. Dent Mater J 2008;27:29-34.

47. Faria KO, Silveira-Júnior CD, Silva-Neto JP, Mattos MG, Marlete Silva MR, Neves FD. Comparison of methods to evaluate implant-abutment interface. Braz J Oral Sci 2013;12:37-40.

48. Alikhasi M, Salehi A, Memarian M, Tabesh M. Diagnostic value of digital radiography in gap detection of implant-abutment connection with zirconia abutments in different vertical x-ray projection angles. J Clin Diag Res 2018;12(5):z15-z18.

49. Ormaechea MB, Millstein P, Hirayama H. Tube angulation effect on radiographic analysis of the implant-abutment interface. Int J Maxillofac Implants 1999;14:77-85.

50. Cameron SM, Joyce A, Brousseau JS, Parker MH. Radiographic verification of implant abutment seating. J Prosthet Dent 1998;79(30):298-303.

51. Liedke G, Spin-Neto R, Silveira H, Wenzel A. Radiographic diagnosis of dental restoration misfit: a systematic review. J Oral Rehabil 2014;41(12):957-67.

52. Cunha TMA, Araujo RPC, Rosha PVB, Amoedo RMP. Comparison of fit accuracy between Procera custom abutments and three implant systems. Clin Implant Dent Rel Res 2012;14:890-895.

53. Zanardi PR, Costa B, Stegun RC, et al. Connecting accuracy of interchanged prosthetic abutments of different dental implants using scanning electron microscopy. Braz Dent J 2012;23:502-7.

54. Fernández M, Delgado L, Molmeneu M, García D, Rodríguez D. Analysis of the misfit of dental implant-supported prosthesis made with three manufacturing processes. J Prosthet Dent 2014;111:116-123.

55. Rismanchian M, Hatami M, Badrian H, Khalighinejad N. Evaluation of microgap size and microbial leakage in the connection area of four abutments with Straumann (ITI) implant. J Oral Implantol 2012;28:677-685.

56. Da Silva-Neto JP, Nobilo MA, Penatti MP, SimamotoJúnior PC . Influence of methodologic aspects on the results on implant-abutment interface microleakage tests: A critical review of in vitro studies. Int J Oral Maxillofac Implants 2012;27:793-800.

57. Seetoh YL, Tan KB, Chua EK, Quek HC, Nicholls JI . Load fatigue performance of conical implant-abutment connections. Int J Oral Maxillofac Implants 2011;26:797-806.

58. Lalithamma JJ, Mallan AS, Murukan SA, Zarina R. A comparative study on microgap of premade abutments and abutments cast in base metal alloys. J Oral Implantol 2014; 40(3):239-49. 